\title{
Optimalisasi Stand-Alone Photovoltaic System dengan Implementasi Algoritma P\&O-Fuzzy MPPT
}

\author{
Dimas Juniyanto $^{1}$, Tatyantoro Andrasto ${ }^{2}$, dan Suryono ${ }^{3}$ \\ Jurusan Teknik Elektro, Fakultas Teknik, Universitas Negeri Semarang \\ Kampus Sekaran, Gunungpati, Semarang, 50229, Indonesia \\ dimas.juniyanto@students.unnes.ac.id ${ }^{1}$,tatyantoro@mail.unnes.ac.id ${ }^{2}$, suryote@yahoo.com ${ }^{3}$
}

\begin{abstract}
The need for electrical energy continues to increase every time. Concerns about the depletion of fossil energy reserves encourage the acceleration of the development of renewable energy use. One of renewable energy is the solar energy. Due to the irreversible irradiation conditions, it takes controls to keep the solar panel's maximum power. The most widely in Maximum Power Point Tracking (MMPT) is Perturb Algorithm and Observe (P\&O) but P\&O Algorithm has deficiency of oscillations when steady state and MPP trace errors when irradiation changes rapidly. In this paper proposed $P$ \& 0 -Fuzzy algorithm is a modification of conventional $P \& O$ to improve the efficiency of solar panels. This research uses Matlab for simulation and hardware implementation using microcontroller Arduino Uno and buck converter topology. The result of simulation and hardware implementation, conventional $P \& O$ has an average efficiency of 85.03\% while MPPT modification with $P$ \& O-Fuzzy algorithm can improve MPP tracking efficiency with $89.67 \%$.
\end{abstract}

Keywords- MPPT, P\&O, Fuzzy, Arduino, Matlab

\begin{abstract}
Abstrak - Kebutuhan energi listrik terus meningkat setiap waktu. Kekhawatiran menipisnya cadangan energi fosil mendorong percepatan pengembangan penggunaan energi terbarukan. Salah satu energi terbarukan yang banyak dikembangkan adalah energi matahari. Karena keadaan iradiasi yang berubah-ubah dan tidak konstan menyebabkan dibutuhkan kontrol untuk tetap menghasilkan daya maksimal panel surya. Maximum Power Point Tracking (MPPT) yang banyak digunakan adalah menggunakan algoritma Perturb and Observe (P\&O), tetapi algoritma P\&O memiliki kekurangan yaitu terjadi osilasi saat steady state dan kesalahan penelusuran MPP ketika iradiasi berubah secara cepat. Pada artikel ini algoritma P\&O-Fuzzy yang diajukan merupakan modifikasi dari P\&O konvesional untuk meningkatkan efisiensi panel surya. Penelitian ini menggunakan software Matlab untuk simulasi dan implementasi hardware menggunakan mikrokontroler Arduino Uno dan topologi buck converter. Hasil simulasi dan implementasi hardware, P\&O konvensional memiliki efisiensi rata-rata $\mathbf{8 5 , 0 3} \%$ sedangkan modifikasi MPPT dengan algoritma P\&O-Fuzzy mampu meningkatkan efisiensi penelusuran MPP dengan rata-rata efisiensi $89,67 \%$.
\end{abstract}

Kata Kunci- MPPT, P\&O, Fuzzy, Arduino, Matlab

\section{PENDAhUluan}

Kemajuan yang signifikan telah dibuat selama beberapa tahun terakhir berkaitan dengan penelitian dan pengembangan sistem energi terbarukan [1]. Diantara berbagai opsi energi terbarukan yang ada, energi matahari merupakan sumber energi yang tidak pernah habis dan energi potensial yang ramah lingkungan [2] sehingga menjadi isu menarik berkaitan perlindungan lingkungan [3]. Energi matahari menjadi salah satu energi terbarukan yang paling cepat berkembang [4] dan menjadi solusi yang sangat menjanjikan [5].

Panel surya memiliki karakteristik output yang nonlinier dipengaruhi oleh iradiasi, suhu, dan impedansi beban. Daya maksimal panel surya didapatkan ketika berada pada titik operasi tertentu yang disebut Maximum Power Point (MPP). Jadi, MPPT dibutuhkan untuk mencari MPP ketika suhu dan atau iradiasi berubah [5].

Banyak algoritma MPPT yang dapat diimplementasikan [6]. Hill Climbing (P\&O), Incremental Conductance, Fractional
Short Circuit Current, Fractional Open Circuit Voltage, Neural Network [7], Modified P\&O [6], [8] dan algoritma Fuzzy Logic [5], [9]-[12] yang bertujuan meningkatkan performa penelusuran MPP. Perbandingan algoritma pada [7], [13], [14] dilakukan untuk mengetahui performa algoritma. Setiap algoritma memiliki kelebihan dan kekurangan masingmasing.

Perubahan iradiasi sebanding dengan perubahan MPP panel surya. Diperlukan penulusuran MPP yang dapat menyesuaikan dengan kecepatan dan arah perubahan iradiasi. Osilasi steady states dan kesalahan penelusuran MPP akan berakibat pada penurunan efisiensi panel surya. Pada penelitian ini penulis mengajukan algoritma P\&O-Fuzzy. Algoritma ini merupakan modifikasi dari algoritma $\mathrm{P} \& \mathrm{O}$ konvensional dengan logika fuzzy yang didesain untuk memperbaiki osilasi steady states dan kesalahan penelusuran MPP pada perubahan iradiasi yang cepat. 


\section{METODE}

DC-DC Converter yang digunakan adalah topologi buck converter, algoritma MPPT memiliki dua masukan berupa tegangan dan arus yang akan diolah datanya menggunakan arduino kemudian dihasilkan sinyal PWM dengan nilai dutycycle seuai dengan algoritma. Beban baterai $12 \mathrm{~V}$ diganti dengan menggunakan Resistor 2,9 $\Omega$. Gambar 1. menunjukkan bagan Stand-Alone Photovoltaic System. Simulasi algoritma MPPT menggunakan Matlab seperti pada Gambar 2.

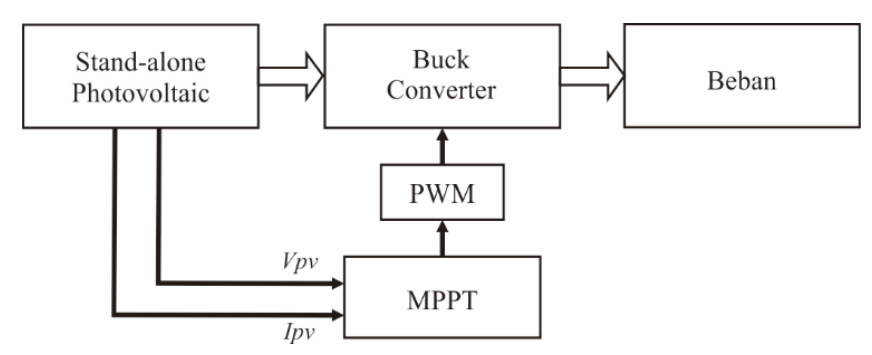

Gambar 1. Bagan Stand-Alone Photovoltaic System

\section{A. Algoritma P\&O-Fuzzy}

Algoritma $\mathrm{P} \& \mathrm{O}$ selain murah juga memiliki tingkat kerumitan lebih rendah sehingga lebih mudah untuk diimplementasikan. Algoritma $\mathrm{P} \& \mathrm{O}$ memiliki dua variabel input yaitu tegangan dan arus sedangkan daya output diperoleh dari hasil perkalian antara tegangan dengan arus PV [6]. Daerah kerja MPPT ditunjukkan pada Gambar 3.

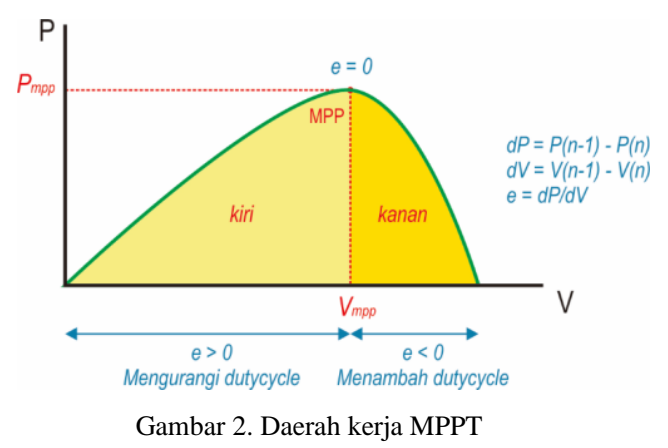

MPPT dengan algoritma $P \& O-F u z z y$ yang penulis ajukan merupakan modifikasi algoritma $\mathrm{P} \& \mathrm{O}$ konvensional dengan menambahkan logika fuzzy pada variabel error dan deltaerror di dalam algoritma yang dibuat.

Fuzzy Logic Control ditambahkan pada algoritma ini untuk menentukan besar dan arah perturbation size dengan mempertimbangkan besar nilai error. Ketika error bernilai positif (+), artinya daerah kerja masih berada di sebelah kiri MPP. Sebaliknya jika error bernilai negatif (-), artinya daerah kerja masih berada di sebelah kanan MPP. Berdasarkan nilai error inilah digunakan sebagai variabel untuk menentukan besarnya nilai increment perturbation size.

Permodelan sistem logika fuzzy yang digunakan adalah sistem fuzzy menggunakan metode Mamdani. Sistem fuzzy yang dibangun terdiri dari dua variabel input yaitu error (e) dan deltaerror (de) serta menghasilkan satu keluaran nilai crips yang mengatur increment duty cycle (I) sinyal PWM yang dibangkitkan mikrokontroler. Desain sistem logika fuzzy yang digunakan ditunjukkan pada Gambar 4. Flowchart algoritma P\&O-Fuzzy ditunjukkan pada Gambar 5.

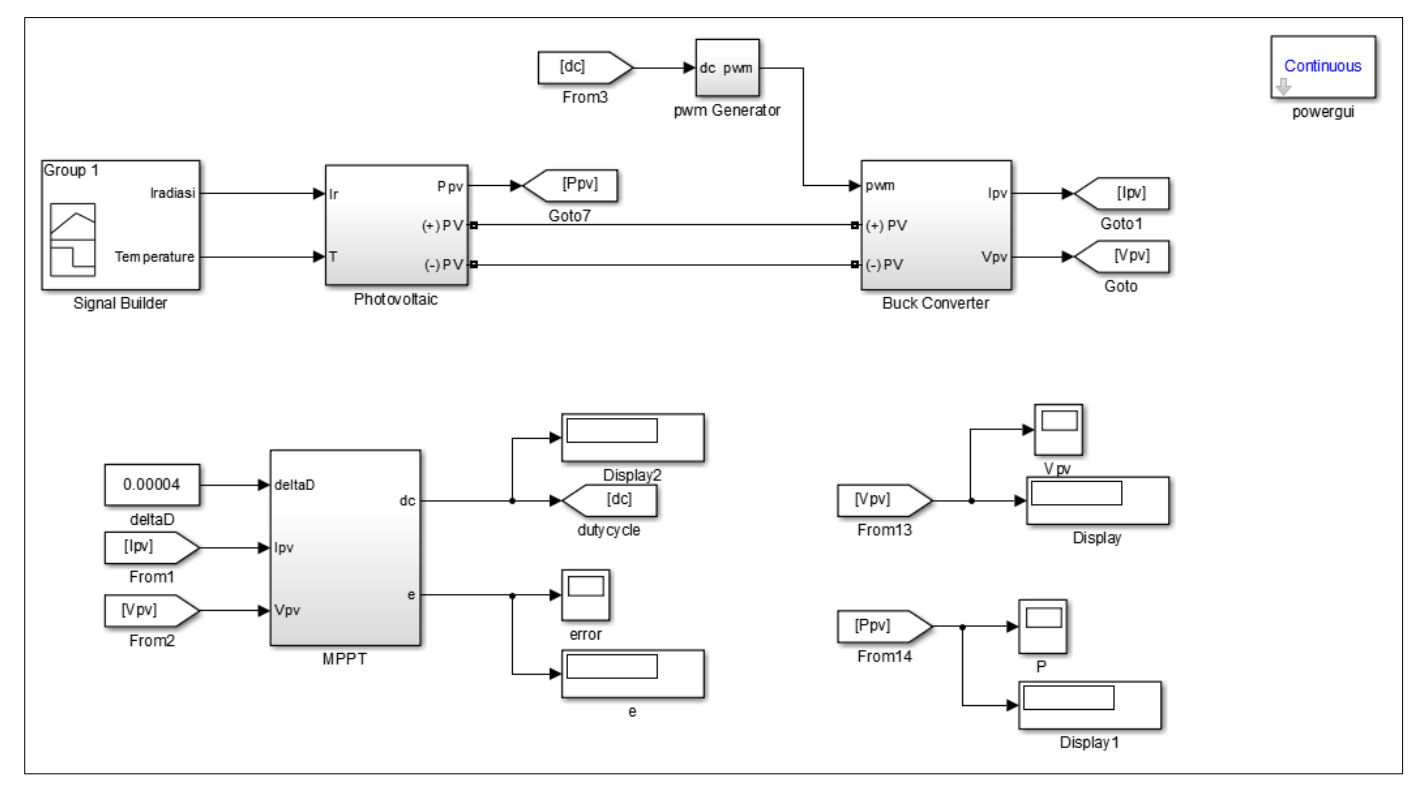

Gambar 3. Simulasi MPPT 


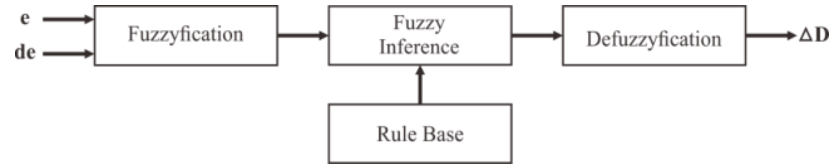

Gambar 4. Desain Logika Fuzzy pada MPPT

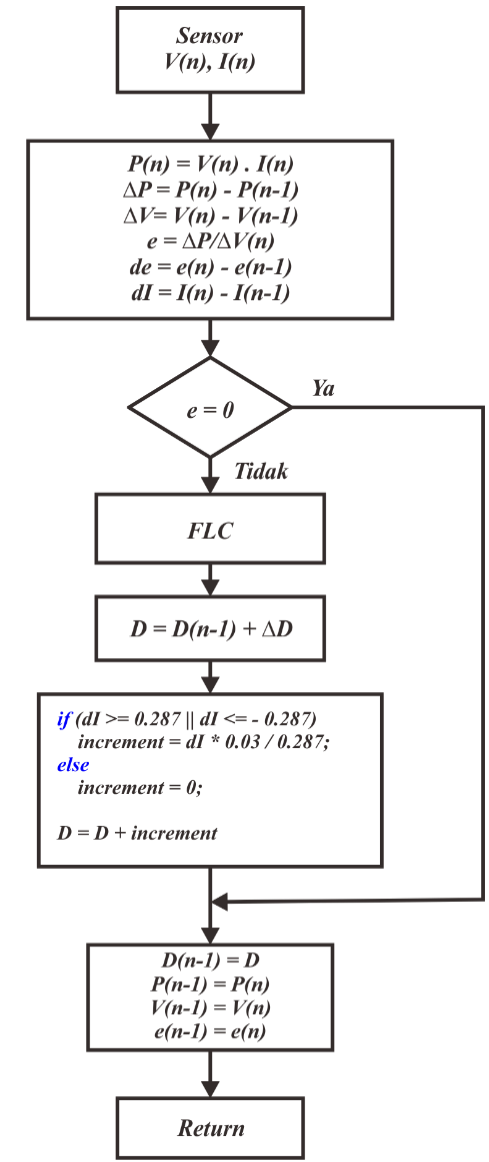

Gambar 5. Flowchart algoritma P\&O-Fuzzy

Fuzzyfikasi dalam perancangan sistem kendali ini adalah dengan merubah nilai error dan deltaerror menjadi nilai masukan fuzzy.

Membership function input error dan deltaerror dibagi menjadi tujuh bagian yaitu Negative Big Error (nbe), Negative Medium Error (nme), Negative Small Error (nse), Zero Error (ze), Positive Small Error (pse), Positive Medium Error (pme), dan Positive Big Error (pbe) dengan fungsi keanggotaan berbentuk kurva segitiga dan trapesium. Fungsi keanggotaan error dan deltaerror ditunjukkan pada Gambar 6 dan Gambar 7.

Variabel input dibentuk menjadi himpunan fuzzy dengan membagi anggota input yang akan menjadi masukan sistem logika fuzzy.

Output sistem logika fuzzy yang dibuat berupa nilai increment duty cycle $(\Delta \mathrm{D}) \mathrm{PWM}$. Membership function output increment duty cycle dibagi menjadi tujuh bagian yaitu Negative Big Increment (NBI), Negative Medium Increment (NMI), Negative Small Increment (NSI), Zero Increment (ZI), Positive Small Increment (PSI), Positive Medium Increment
(PMI), dan Positive Big Increment (PBI) dengan fungsi keanggotaan berbentuk kurva segitiga. Pembentukan himpunan fuzzy output increment duty cycle ditunjukkan pada Gambar 8.

Aturan dasar atau rule base pada kontrol logika fuzzy merupakan suatu bentuk aturan relasi/implikasi "Jika-Maka" atau "If-Then". Rancangan sistem logika fuzzy memiliki 49 rule base seperti ditunjukkan pada Tabel I. Berdasarkan proses rule base yang telah dilakukan didapatkan rule viewer sistem fuzzy seperti ditunjukkan pada Gambar 9.
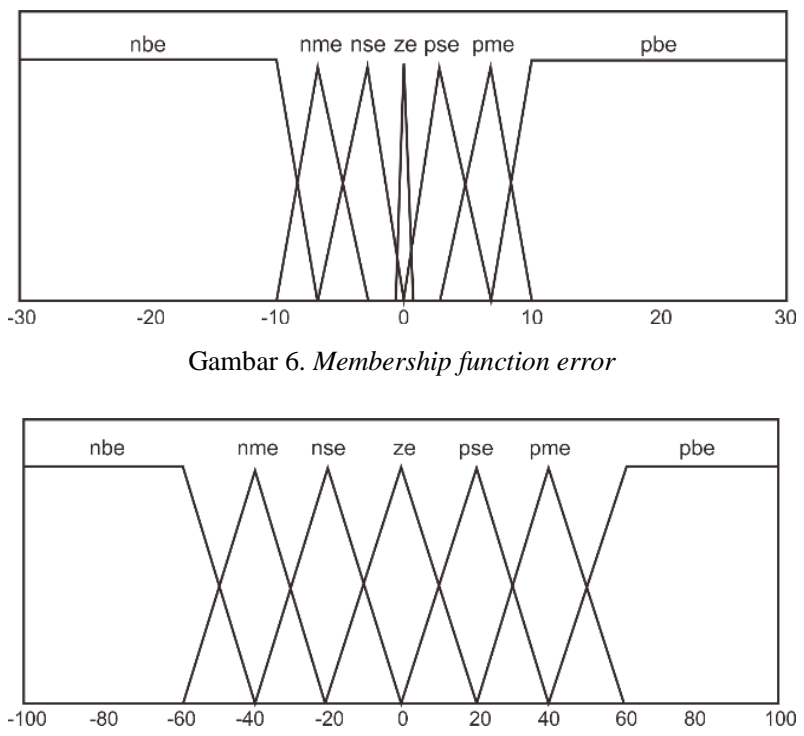

Gambar 7. Membership function deltaerror

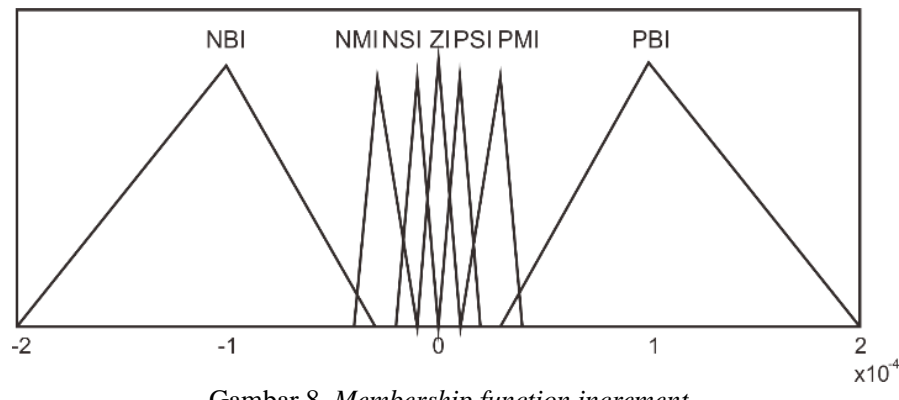

Gambar 8. Membership function increment

TABEL I. RULE BASED

\begin{tabular}{|c|c|c|c|c|c|c|c|}
\hline e/de & pbe & pme & pse & ze & nse & nme & nbe \\
\hline pbe & NBI & NBI & NBI & NBI & NMI & NSI & ZE \\
\hline pme & NBI & NMI & NBI & NMI & NSI & ZI & PSI \\
\hline pse & NBI & NMI & NMI & NSI & ZI & PZI & PSI \\
\hline ze & NMI & NMI & NSI & ZI & PSI & PMI & PMI \\
\hline nse & NSI & NSI & NSI & PSI & PSI & PMI & PBI \\
\hline nme & NSI & ZI & ZI & PMI & PMI & PMI & PBI \\
\hline nbe & ZI & PSI & PSI & PBI & PBI & PBI & PBI \\
\hline
\end{tabular}




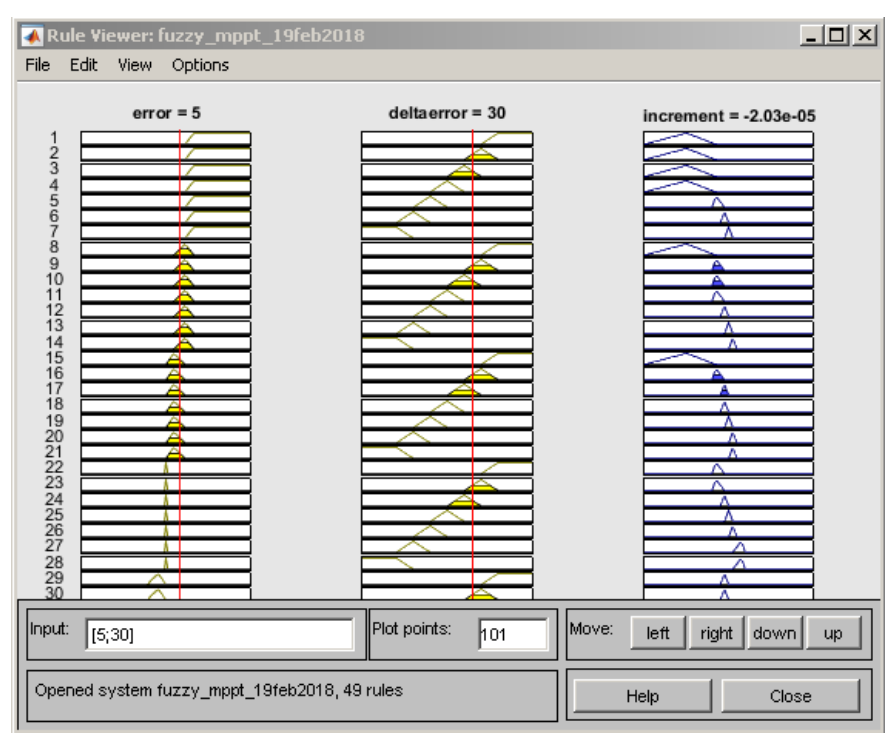

Perubahan nilai arus yang terukur dijadikan sebagai indikasi telah terjadi perubahan iradiasi. Sesuai dengan spesifikasi panel surya yang akan digunakan, $\mathrm{I}_{\text {mpp }}$ panel surya SUOER $50 \mathrm{WP}$ adalah 2,87 A. Artinya ketika iradiasi (G) pada keadaan maksimal $1000 \mathrm{~W} / \mathrm{m}^{2}$ dan titik kerja pada MPP maka arus yang akan mengalir sebesar 2,87 A. Hal ini ditunjukkan pada persamaan 1. Perubahan iradiasi $(\Delta G)$ dikelompokan menjadi dua bagian, perubahan iradiasi kecil ketika nilai $\Delta \mathrm{G}<100 \mathrm{~W} / \mathrm{m}^{2}$ dan perubahan iradiasi besar ketika nilai $\Delta \mathrm{G}>=100 \mathrm{~W} / \mathrm{m}^{2}$. Setiap penurunan atau kenaikan $100 \mathrm{~W} / \mathrm{m}^{2}$ arus yang mengalir juga akan turun atau naik sebesar 1/10 arus maksimal atau sebesar 0,287 A.

$$
\frac{\Delta \mathrm{G}}{1000}=\frac{\mathrm{dI}}{I_{M P P}}
$$

Sesuai dengan persamaan 1, perubahan dI digunakan sebagai pengubah nilai perturbation size dengan mempertimbangkan besar perubahan iradiasi.

Gambar 9. Rule viewer

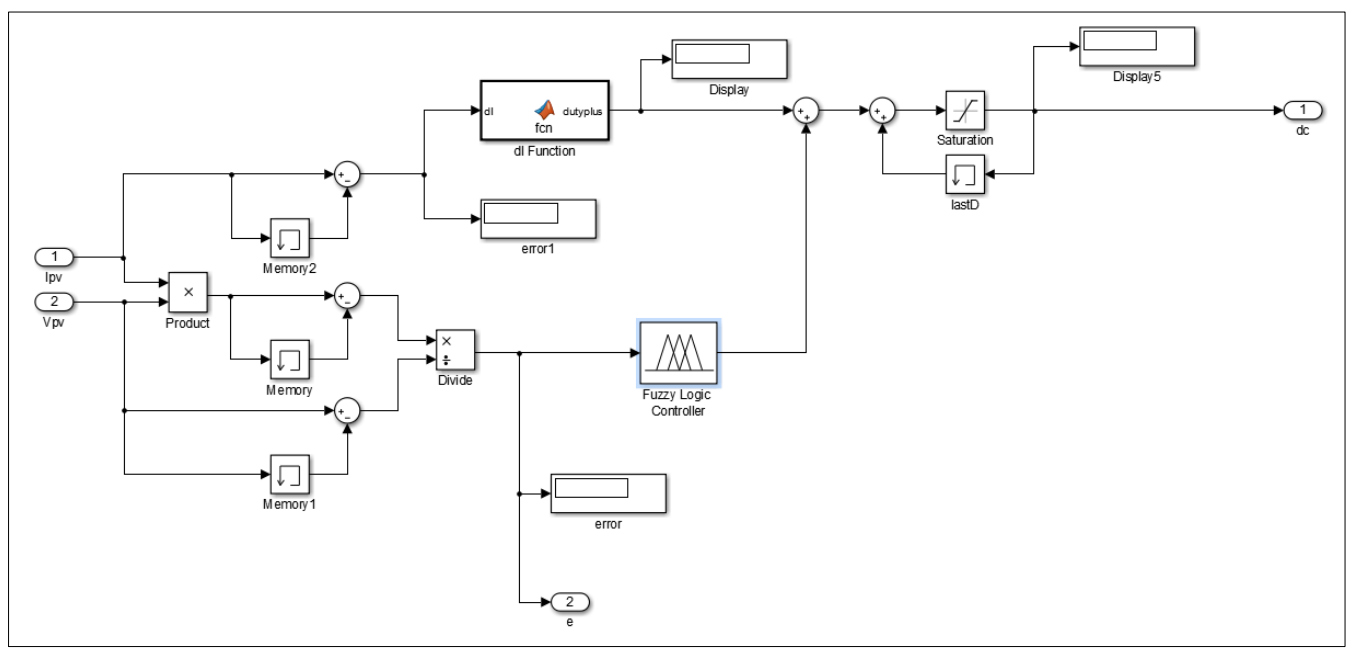

Gambar 10. Detail simulasi algoritma P\&O-Fuzzy

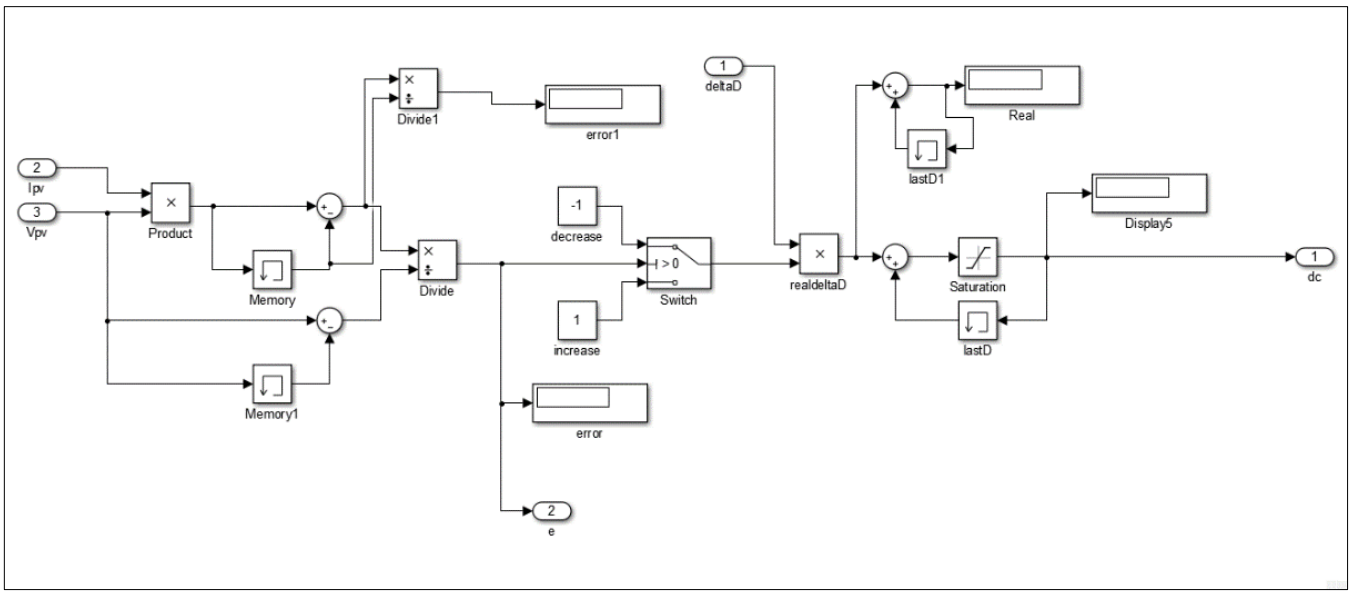

Gambar 11. Detail simulasi algoritma P\&O konvensional 
Detail Simulasi Algoritma P\&O-Fuzzy ditunjukkan pada Gambar 10. Berdasarkan hasil pengujian simulasi didapatkan data dutycycle pada iradiasi $1000 \mathrm{~W} / \mathrm{m}^{2}$, dutycycle saat mencapai titik MPP sebesar 0,65 sedangkan saat iradiasi diturunkan menjadi $900 \mathrm{~W} / \mathrm{m}^{2}$, dutycycle saat mencapai titik MPP sebesar 0,62. Setiap perubahan $100 \mathrm{~W} / \mathrm{m}^{2}$ terjadi perubahan dutycycle sebesar 0,03. Karena perubahan dutycycle berbanding lurus dengan perubahan arus dan perubahan iradiasi sehingga besar nilai increment dapat diperoleh dengan persamaan 2 .

$$
\text { increment }=\frac{\mathrm{dI}}{I_{M P P}} \times 0,03
$$

B. Algoritma P\&O Konvensional

Algoritma $\mathrm{P} \& \mathrm{O}$ konvensional memiliki perbedaan dimana besar nilai perturbation size tetap. Algoritma ini memiliki keunggualan pada kondisi iradiasi yang cenderung konstan dan tidak berubah-ubah secara cepat. Simulasi algoritma P\&O konvensional ditunjukan pada Gambar 11.

\section{Buck Converter}

Buck converter adalah sebuah rangkaian elektronik yang berfungsi untuk menghasilkan keluaran tegangan yang nilainya lebih rendah dibandingkan dengan nilai tegangan masukan. Perancangan buck converter menggunakan simulasi ISIS Proteus untuk validasi performa rangkaian.

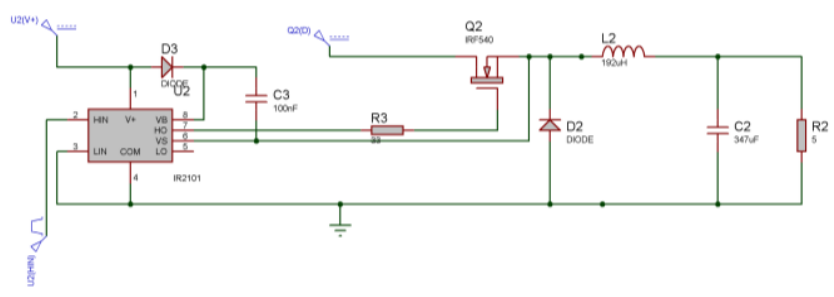

Gambar 12. Rangkaian buck converter

Berdasarkan Gambar 12 buck converter terdiri dari input panel surya, komponen utama yang terdiri dari kapasitor, induktor dan saklar. Saklar menggunakan komponen semikonduktor mosfet yang akan terbuka dan tertutup dengan memberikan sinyal PWM ke kaki gate. Karena rangkaian buck converter menggunakan mosfet tipe $\mathrm{N}$-chanel maka dibutuhkan komponen tambahan yaitu IC IR2101 yang digunakan sebagai high-side driver mosfet dengan menggunakan teknik bootstrapping. Parameter rancangan buck converter ditunjukkan pada Tabel II.

TABEL II. PARAMETER BUCK CONVERTER

\begin{tabular}{|c|l|c|}
\hline No & \multicolumn{1}{|c|}{ Parameter } & Nilai \\
\hline 1 & Vin & $18 \mathrm{~V}$ \\
\hline 2 & Vout & $12 \mathrm{~V}$ \\
\hline 3 & Arus output & $4,167 \mathrm{~A}$ \\
\hline 4 & Frekuensi switching & $25 \mathrm{Khz}$ \\
\hline
\end{tabular}

1) Dutycycle

$$
D=\frac{\text { Vout }}{\text { Vin }}=\frac{12}{18}=0,67
$$

2) Inductor

$$
\begin{aligned}
& \Delta I L=0,2 \times I o \\
& \Delta I L=0,2 \times 4,167 \\
& \Delta I L=0,8334 \\
& L=\frac{\text { Vo } \times(\text { Vin }- \text { Vo })}{\Delta I L \times f s \times \text { Vin }} \\
& L=\frac{12 \times(18-12)}{0,8334 \times 25000 \times 18} \\
& L=\frac{72}{375030} \\
& L=192 \mathrm{uH}
\end{aligned}
$$

3) Capacitor

$$
\begin{aligned}
C & =\frac{\Delta I L}{8 \cdot f \cdot \Delta V o} \\
C & =\frac{0,8334}{8 \times 25000 \times 0,1 \% \times 12} \\
C & =\frac{0,8334}{2400} \\
C & =347,25 u F
\end{aligned}
$$

\section{Sensor Tegangan}

Input tegangan yang masuk ke mikrokontroler maksimal 5 V $40 \mathrm{~mA}$, sehingga diperlukan penurun tegangan untuk bisa mengukur tegangan yang lebih besar dengan memanfaatkan pin ADC mikrokontroler. Rangkaian sensor tegangan ditunjukkan pada Gambar 13.

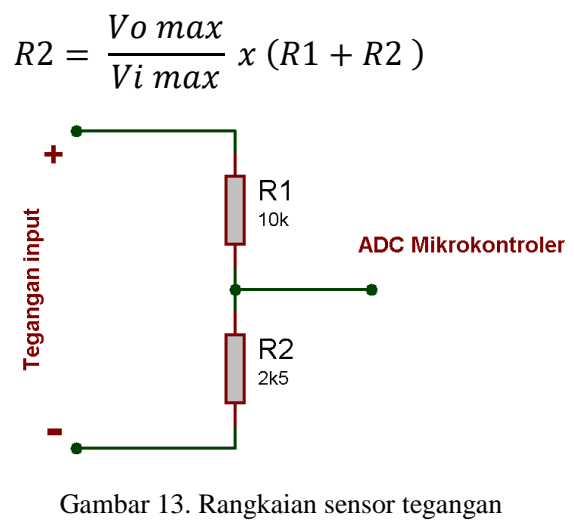

Berikut ini parameter yang harus ditentukan terlebih dahulu dalam membuat rangkaian pembagi tegangan:

$$
\begin{array}{ll}
\text { Vi max } & : 25 \mathrm{~V} \\
\text { Vo max } & : 5 \mathrm{~V} \\
\text { R1 } & : 10.000 \Omega
\end{array}
$$

Dengan menggunakan persamaan 3 sehingga diperoleh nilai R2 sebagai berikut:

$$
\begin{aligned}
& \mathrm{R} 2=\frac{5}{25} \times(10.000+\mathrm{R} 2) \\
& \mathrm{R} 2=2500 \Omega
\end{aligned}
$$




\section{HASIL DAN PEMBAHASAN}

Pembahasan mengenai hasil penelitian yang telah dilakukan terbagi menjadi dua bagian yaitu hasil perancangan simulasi dengan menggunakan software Matlab dan hasil secara hardware dengan menggunakan Arduino. Implementasi algoritma MPPT secara hardware pada penelitian ini menggunakan topologi buck converter. Hardware ditunjukkan pada Gambar 14 dengan spesifikasi seperti ditunjukkan pada Tabel III.

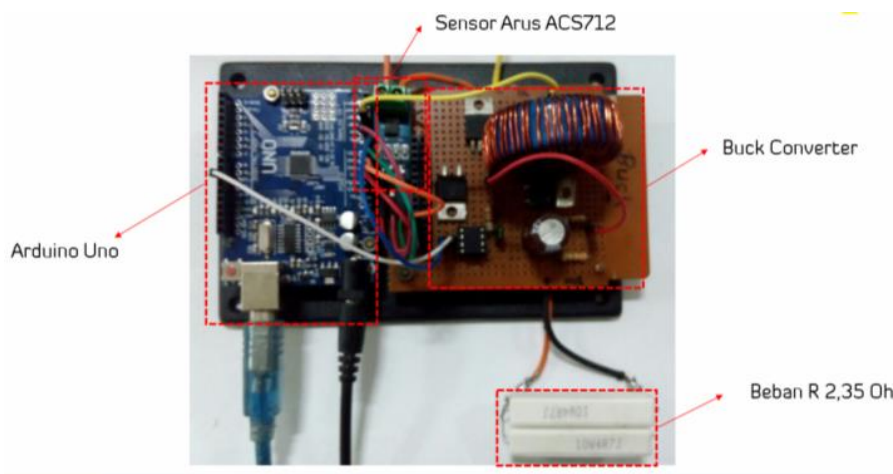

Gambar 14. Implementasi hardware MPPT

TABEL III. SPESIFIKASI HARDWARE

\begin{tabular}{|c|l|l|}
\hline No & \multicolumn{1}{|c|}{ Komponen } & \multicolumn{1}{c|}{ Spesifikasi } \\
\hline 1 & Arduino & UNO R.3 \\
\hline 2 & Sensor Arus & ACS $71230 \mathrm{~A}$ \\
\hline 3 & Sensor Tegangan & $\mathrm{R} 1=10 \mathrm{k} \Omega, \mathrm{R} 2=2 \mathrm{k} 2 \Omega$ \\
\hline 4 & $\mathrm{~L}$ & $192 \mathrm{uH}$ \\
\hline 5 & $\mathrm{C}$ & $470 \mathrm{uF}$ \\
\hline 6 & $\mathrm{R}$ & $2.35 \Omega$ \\
\hline 7 & Dioda & MUR1560 \\
\hline 8 & Mosfet & IRF540 \\
\hline 9 & Driver Mosfet & IR2101 \\
\hline
\end{tabular}

Ragkaian dibagi menjadi tiga blok utama terdiri dari blok algoritma MPPT, buck converter dan beban. Blok algoritma MPPT terdiri dari sensor arus, sensor tegangan, dan arduino. Data sensor arus dihubungkan dengan pin A0, data sensor tegangan dihubungkan dengan pin A1 arduino. Blok buck converter adalah rangkaian dc-dc converter yang menghasilkan tegangan keluaran lebih kecil dari tegangan masukanya. Blok beban berupa resistor $2,9 \Omega$.

\section{A. Pengujian Simulasi}

Pengujian performa implementasi algoritma P\&O-Fuzzy dan P\&O konvensional dilakukan dengan menggunakan software Matlab 2015b sesuai dengan desain simulasi pada Gambar 2 dengan detail desain simulasi masing-masing algoritma ditunjukkan pada Gambar 10 dan Gambar 11. Simulasi dilakukan dengan parameter seperti ditunjukkan pada Tabel IV.

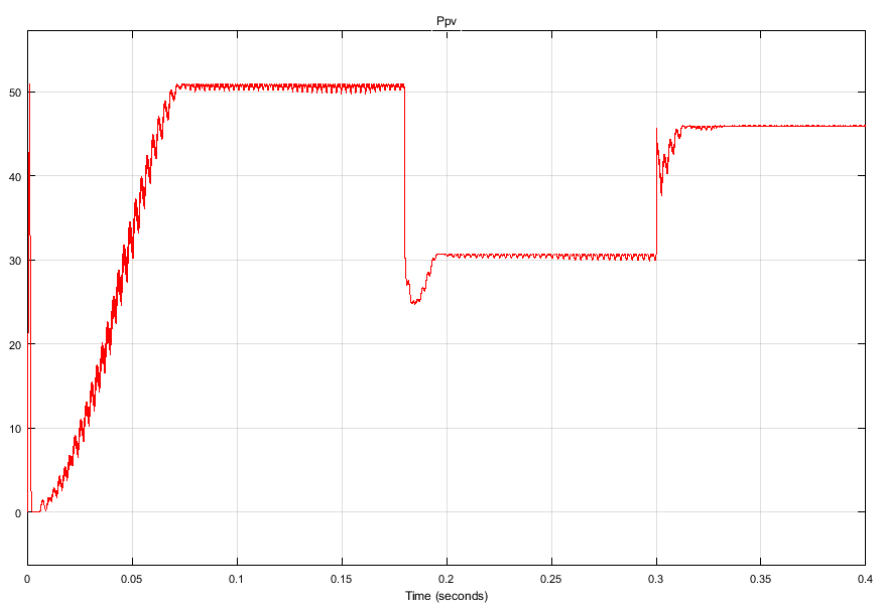

Gambar 15. Hasil simulasi algoritma P\&O konvensional

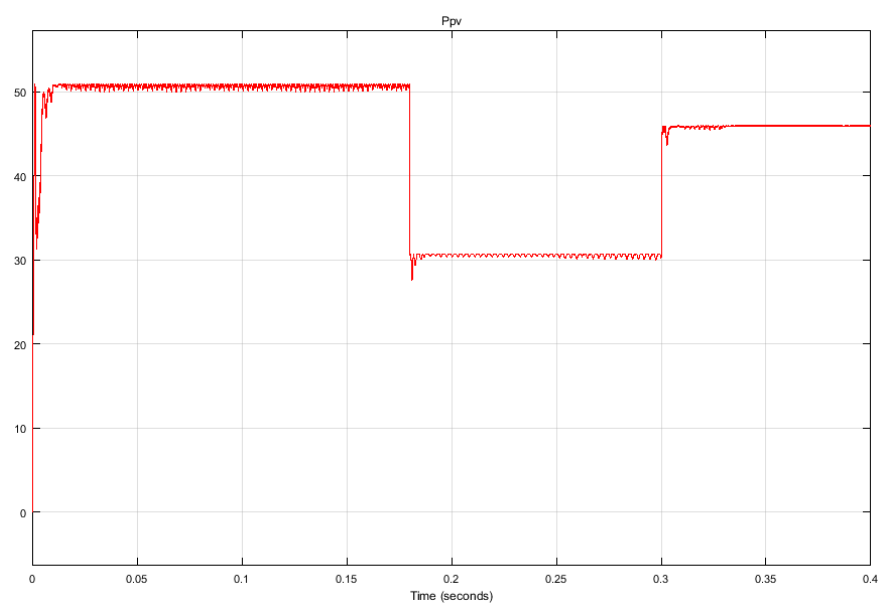

Gambar 16. Hasil simulasi algoritma P\&O-Fuzzy

TABEL IV. PARAMETER SiMUlasi

\begin{tabular}{|c|l|l|}
\hline No & Indikator & Keterangan \\
\hline 1 & Time step & $10 \mathrm{us}$ \\
\hline 2 & Total time & $0,4 \mathrm{~s}$ \\
\hline 3 & Load & $\mathrm{R}=2,9 \Omega$ \\
\hline 4 & Iradiasi & $\begin{array}{l}1000 \mathrm{~W} / \mathrm{m}^{2}, 600 \mathrm{~W} / \mathrm{m}^{2}, 900 \\
\mathrm{~W} / \mathrm{m}^{2}\end{array}$ \\
\hline
\end{tabular}

Berdasarkan hasil simulasi yang ditunjukan Gambar 15 dan Gambar 16 diperoleh dua hasil MPPT dengan algoritma yang berbeda. Gambar 15 menunjukan hasil simulasi dengan menggunakan algoritma $\mathrm{P} \& \mathrm{O}$ konvensional sedangkan Gambar 16 menunjukan hasil simulasi dengan menggunakan algoritma P\&O-Fuzzy.

P\&O konvensional memiliki kekurangan waktu tracking yang lambat dan terjadi kesalahan tracking ketika iradiasi berubah secara konstan seperti yang ditunjukan pada Gambar 15. Dengan menggunakan algoritma P\&O konvensional sebenarmya bisa mempersingkat waktu pencarian atau tracking MPP dengan cara memperbesar perturbation size, tetapi hal ini akan berpengaruh terhadap besar osilasi pada saat mencapai titik MPP, semakin besar perturbation size semakin besar pula osilasinya. 
P\&O-Fuzzy adalah pengembangan dari algoritma $\mathrm{P} \& \mathrm{O}$ konvensional dengan mengimplementasikan logika fuzzy untuk menentukan besar perturbation size dengan variabel acuanya besar nilai error dan deltaerror. Berdasarkan Gambar 16 dapat dilihat algoritma P\&O-Fuzzy mampu memepersingkat waktu tracking MPP dan memperbaiki error tracking saat terjadi perubahan iradiasi dengan cepat.

\section{B. Pengujian Sinyal PWM}

Pulse Width Modulation (PWM) merupakan sebuah mekanisme untuk membangkitkan sinyal keluaran yang periodenya berulang antara high dan low dimana kita dapat mengontrol durasi sinyal high dan low sesuai dengan yang kita inginkan. Duty cycle merupakan persentase periode sinyal high dan periode sinyal low, persentase duty cycle akan bebanding lurus dengan tegangan rata-rata yang dihasilkan. Besar nilai duty cycle menunjukan persentase waktu high $\left(\mathrm{T}_{\mathrm{on}}\right)$ dalam satu detakan sinyal PWM yang dihasilkan.

Hasil pengujian sinyal PWM menggunakan osciloscope untuk melihat bentuk sinyal output dari arduino pin 10 dengan variasi nilai duty cycle ditunjukkan pada Tabel V.

TABEL V. HASIL PENGUJIAN SINYAL PWM

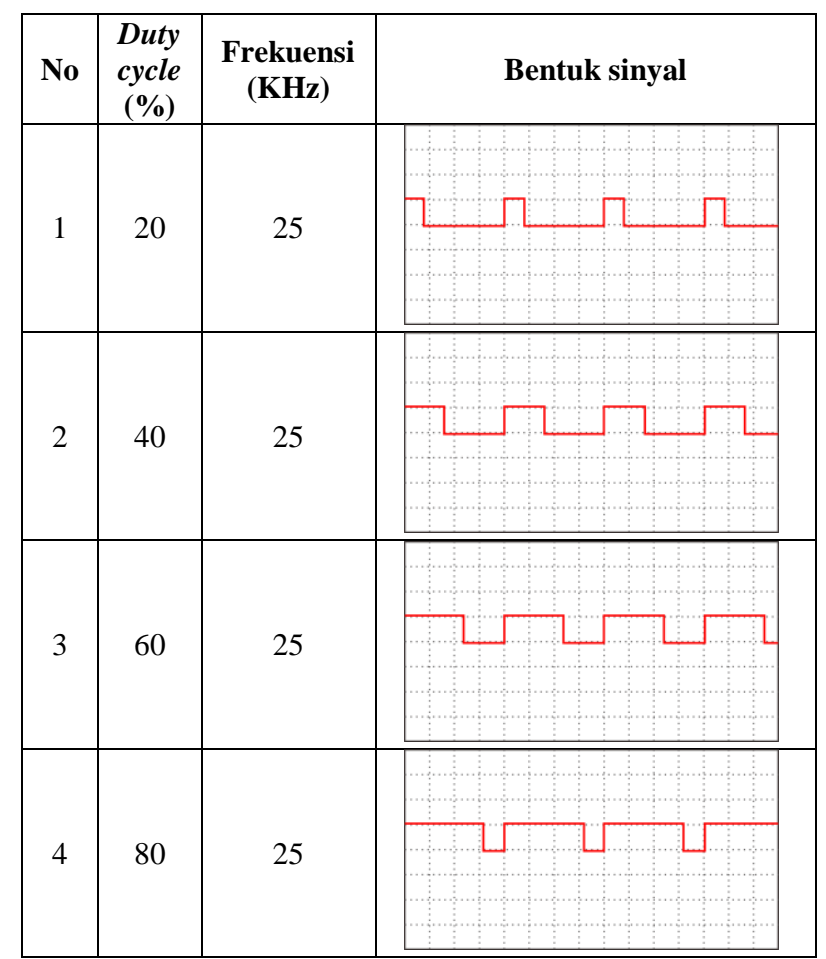

Penelitian ini membutuhkan PWM dengan frekuensi 25 $\mathrm{kHz}$ untuk switching Mosfet buck converter. Untuk menghasilkan PWM dengan frekuensi $25 \mathrm{kHz}$ diperlukan modifikasi PWM arduino melalui program untuk mengubah frekuensi PWM bawaan. Pengubahan frekuensi PWM akan berpengaruh terhadap fungsi millis, delay, dan servo.

Berdasarkan data yang diperoleh pada Tabel V dan Tabel VI dapat disimpulkan Arduino mampu menghasilkan sinyal PWM mendekati sempurna dengan sinyal PWM yang didesain sebelumnya.
TABEL VI. PARAMETER SINYAL PWM

\begin{tabular}{|c|l|l|l|}
\hline No & Indikator & \multicolumn{1}{|c|}{ Teori } & \multicolumn{1}{c|}{ Praktik } \\
\hline 1 & Vmax & $5 \mathrm{~V}$ & $5,20 \mathrm{~V}$ \\
\hline 2 & Vmin & $0 \mathrm{~V}$ & $-200 \mathrm{mV}$ \\
\hline 3 & Frekuensi & $25 \mathrm{kHz}$ & $24,88 \mathrm{kHz}$ \\
\hline 4 & Periode & $40 \mathrm{us}$ & $40,2 \mathrm{us}$ \\
\hline
\end{tabular}

\section{Pengujian Buck Converter}

Hasil pengujian rangkaian buck converter dengan variabel duty cycle yang berbeda ditunjukkan pada Tabel VII. Pengujian rangkaian buck converter menggunakan beban resistor 5 $\Omega$. Sesuai Tabel II, buck converter di desain dengan Vin $18 \mathrm{~V}$ akan menghasilkan Vout $12 \mathrm{~V}$ dengan besar duty cycle sesuai perhitungan $67 \%$.

Hasil pengukuran buck converter dibandingkan dengan hasil simulasi rangkaian menggunakan ISIS Proteus. Berdasarkan Tabel VII diperoleh data yang menunjukan semakin kecil dutycycle maka tegangan keluaran semakin kecil dan berlaku sebaliknya, semakin besar nilai dutycyle tegangan yang dihasilkan semakin besar mendekati tegangan asli masukan.

TABEL VII. HASIL PENGUJIAN BUCK CONVERTER

\begin{tabular}{|c|c|c|c|c|c|}
\hline No & $\begin{array}{c}\text { Duty } \\
\text { cycle } \\
(\boldsymbol{\%})\end{array}$ & Vin (V) & $\begin{array}{c}\text { Vout } \\
\text { Simulasi } \\
(\mathbf{V})\end{array}$ & $\begin{array}{c}\text { Vout } \\
\text { Praktik } \\
(\mathbf{V})\end{array}$ & $\begin{array}{c}\text { Error } \\
(\mathbf{V})\end{array}$ \\
\hline 1 & 20 & 18 & 3,28 & 2,5 & 0,78 \\
\hline 2 & 40 & 18 & 6,85 & 5,85 & 1 \\
\hline 3 & 60 & 18 & 10,3 & 9,34 & 0,96 \\
\hline 4 & 80 & 18 & 13,7 & 12,85 & 0,85 \\
\hline 5 & 90 & 18 & 15,4 & 14,78 & 0,66 \\
\hline
\end{tabular}

D. Pengujian Sensor Arus

Sensor arus yang digunakan pada penelitian ini adalah ACS712 30A. Sensor ini memiliki kemampuan membaca arus dengan rentang nilai 0-30 A. Berdasarkan hasil pengujian yang penulis lakukan untuk mengetahui perbandingan tingkat kepresisian sensor, sensor arus ACS712 30A memiliki tingkat presisi yang lebih tinggi dibandingkan dengan ACS712 versi $5 \mathrm{~A}$ dan 20A.

Pengujian sensor arus dengan menggunakan sumber power suplay dan beban resistor $33,3 \Omega$. Hasil pengujian sensor arus terhadap masukan beban dengan arus yang bervariasi ditunjukkan pada Tabel VIII.

TABEL VIII. HASIL PENGUJIAN SENSOR ARUS

\begin{tabular}{|c|c|c|c|}
\hline \multirow{2}{*}{ No } & \multicolumn{2}{|c|}{ Arus (A) } & \multirow{2}{*}{$\begin{array}{c}\text { Error } \\
\text { (A) }\end{array}$} \\
\cline { 2 - 3 } & Power Supply & Sensor & 0,07 \\
\hline 1 & 1 & 1,07 & 0,03 \\
\hline 2 & 1,5 & 1,53 & 0,04 \\
\hline 3 & 2 & 2,04 & 0,06 \\
\hline 4 & 2,5 & 2,56 & 0,04 \\
\hline 5 & 3 & 3,04 & \\
\hline
\end{tabular}


Fungsi transfer dapat didefinisikan sebagai persamaan matematika yang memberikan informasi korelasi antara keluaran dengan masukan dalam suatu sistem. Pada sensor ACS712 ini, fungsi transfer adalah korelasi antara nilai besaran fisis berupa teganan yang terukur oleh sensor terhadap nilai ADC (Analog to Digital Converter) yang terbaca.

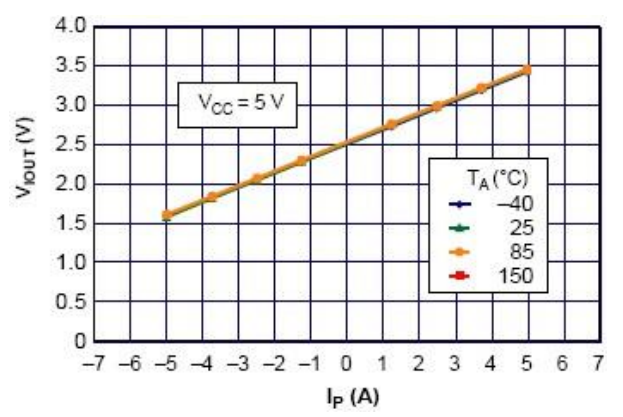

Gambar 17. Grafik keluaran tegangan terhadap arus yang terukur

Berdasarkan Gambar 17, sensor ACS712 pada keadaan tanpa beban atau arus $0 \mathrm{~A}$, tegangan yang terbaca arduino adalah $0,5 \mathrm{Vcc}$ dalam hal ini $5 \mathrm{~V}$. Jadi saat arus 0 A tegangan yang terbaca 2,5 V. Sensitivitas sensor ACS712 30A sebesar $66 \mathrm{mV} / \mathrm{A}$. Setiap perubahan tegangan sebesar $66 \mathrm{mV}$ artinya telah terjadi perubahan arus sebesar 1 A. Berdasarkan Tabel VIII diperoleh data yang menunjukan kemampuan sensor arus ACS712 30A membaca nilai arus dengan tingkat kepresisian yang tinggi dengan error 0,03-0,07 A.

\section{E. Pengujian Sensor Tegangan}

Hasil pengujian sensor tegangan terhadap masukan beban dengan tegangan yang bervariasi ditunjukkan pada Tabel IX.

TABEL IX. Hasil PEngujian SEnsor TEgangan

\begin{tabular}{|c|c|c|c|}
\hline \multirow{2}{*}{ No } & \multicolumn{4}{|c|}{ Hasil Pengukuran } \\
\cline { 2 - 4 } & $\begin{array}{c}\text { Power Supplay } \\
(\mathbf{V})\end{array}$ & $\begin{array}{c}\text { Sensor } \\
(\mathrm{V})\end{array}$ & $\begin{array}{c}\text { Error } \\
(\mathbf{V})\end{array}$ \\
\hline 1 & 6 & 5,98 & 0,02 \\
\hline 2 & 10 & 9,96 & 0,04 \\
\hline 3 & 14 & 14,05 & 0,05 \\
\hline 4 & 18 & 17,99 & 0,01 \\
\hline 5 & 22 & 21,97 & 0,03 \\
\hline
\end{tabular}

Sensor tegangan didesain menggunakan teori pembagi tegangan menggunakan 2 buah resistor, kemudian hasil pembagi tegangan dibaca oleh arduino dengan menggunakan pin ADC. Nilai resistor yang digunakan adalah $\mathrm{R} 1=10 \mathrm{k} \Omega$ dan $\mathrm{R} 2=2 \mathrm{k} 2 \Omega$. Perubahan nilai $\mathrm{R} 2$ memperbesar nilai maksimum tegangan terbaca menjadi $27,72 \mathrm{~V}$. Berdasarkan
Tabel IX diperoleh data yang menunjukan kemampuan sensor tegangan yang dibuat membaca tegangan dengan tingkat kepresisian yang tinggi dengan error $0,01-0,05 \mathrm{~V}$.

\section{F. Pengujian Efisiensi MPPT Algoritma P\&O-Fuzzy}

Pengujian efisiensi alat dilakukan dengan membandingkan dua algoritma MPPT yang berbeda yaitu algoritma P\&O konvensional dan $\mathrm{P} \& \mathrm{O}-$ Fuzzy dengan parameter ukur berupa intensitas cahaya dan iradiasi yang sama. Hasil pengujian efisiensi alat kontrol MPPT dengan algoritma P\&O konvensional dan P\&O-Fuzzy ditunjukkan pada Tabel X.

TABEL X. HASIL PENGUJIAN EFISIENSI MPPT

\begin{tabular}{|c|c|c|c|c|c|c|c|}
\hline \multirow{2}{*}{$\begin{array}{l}\mathbf{N} \\
\mathbf{o}\end{array}$} & \multirow{2}{*}{$\begin{array}{c}\text { Caha } \\
\text { ya } \\
\text { (klux) }\end{array}$} & \multirow{2}{*}{$\begin{array}{l}\text { Iradiasi } \\
\left(\mathbf{W} / \mathbf{m}^{2}\right)\end{array}$} & \multicolumn{3}{|c|}{ Ppv (Watt) } & \multicolumn{2}{|c|}{$\begin{array}{c}\text { Efisiensi } \\
(\%)\end{array}$} \\
\hline & & & Pmax & P\&O & $\begin{array}{l}\text { P\&O- } \\
\text { Fuzzy }\end{array}$ & P\&O & $\begin{array}{l}\text { P\&O- } \\
\text { Fuzzy }\end{array}$ \\
\hline 1 & 25 & 330 & 16,5 & 13,39 & 14,80 & 81,17 & 89,69 \\
\hline 2 & 20 & 280 & 14 & 11,89 & 12,55 & 84,97 & 89,64 \\
\hline 3 & 15 & 230 & 11,5 & 10 & 10,31 & 87,01 & 89,68 \\
\hline 4 & 10 & 185 & 9,25 & 8,05 & 8,29 & 86,98 & 89,68 \\
\hline \multicolumn{6}{|c|}{ Rata-rata } & 85,03 & 89,67 \\
\hline
\end{tabular}

Titik daya maksimal $\left(\mathrm{P}_{\max }\right)$ adalah daya maksimal yang mampu dihasilkan panel surya yang besarnya tergantung pada kondisi iradiasi dan suhu. Nilai acuan penentuan besar $\mathrm{P}_{\max }$ menyesuaikan datasheet panel surya SUOER 50 WP yang digunakan yaitu pada iradiasi $1000 \mathrm{~W} / \mathrm{m}^{2}$ dan suhu $25^{\circ} \mathrm{C}$ panel surya mampu menghasilkan daya 50 Watt. Suhu panel surya pada pengambilan data penelitian ini diantara $32-35^{\circ} \mathrm{C}$.

$$
\begin{gathered}
\text { Pmax }=\frac{\text { Iradiasi }}{1000} \times 50 \text { Watt } \\
\text { Efisiensi MPPT }(\eta)=\frac{P p v}{P \max } \times 100 \% \\
\text { Rata }- \text { rata efisiensi MPPT }\left(\_\eta\right)=\frac{\sum_{i=0}^{n} \eta}{n}
\end{gathered}
$$

$\mathrm{P}_{\max }$ merupakan hasil perhitungan persamaan 4 , efisiensi dengan menggunakan persamaan 5 , dan rata-rata efisiensi panel surya menggunakan persamaan 6. Data yang disajikan pada Tabel X merupakan rata-rata nilai Ppv dari 500 data yang diambil secara berkelanjutan dengan time sampling sebesar $100 \mathrm{~ms}$.

Berdasarkan Tabel X dan Gambar 18 diperoleh data yang menunjukan MPPT dengan algoritma Perturb and ObserveFuzzy mampu meningkatkan efisiensi panel surya dibandingkan dengan algoritma Perturb and Observe konvensional. Efisiensi rata-rata yang dihasilkan algoritma P\&O konvensional 85,03 \% sedangkan algoritma P\&O-Fuzzy meningkat menjadi $89,67 \%$. 

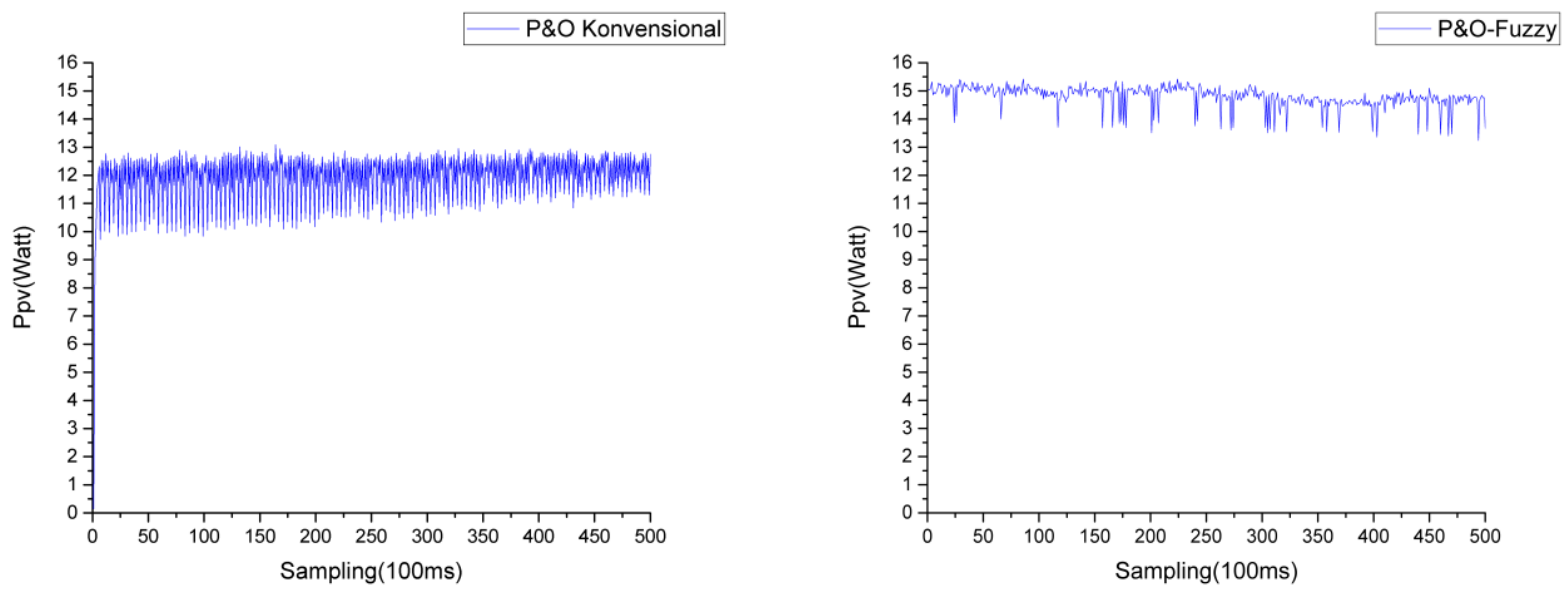

(a)
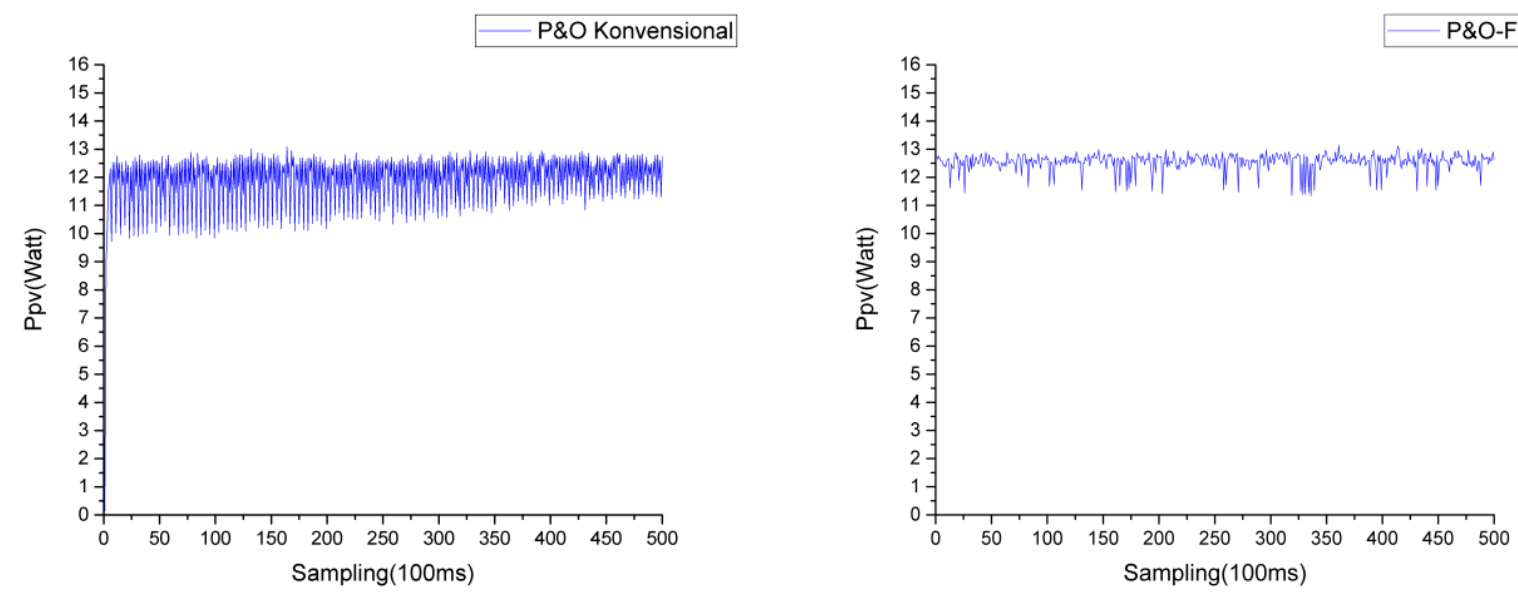

(b)
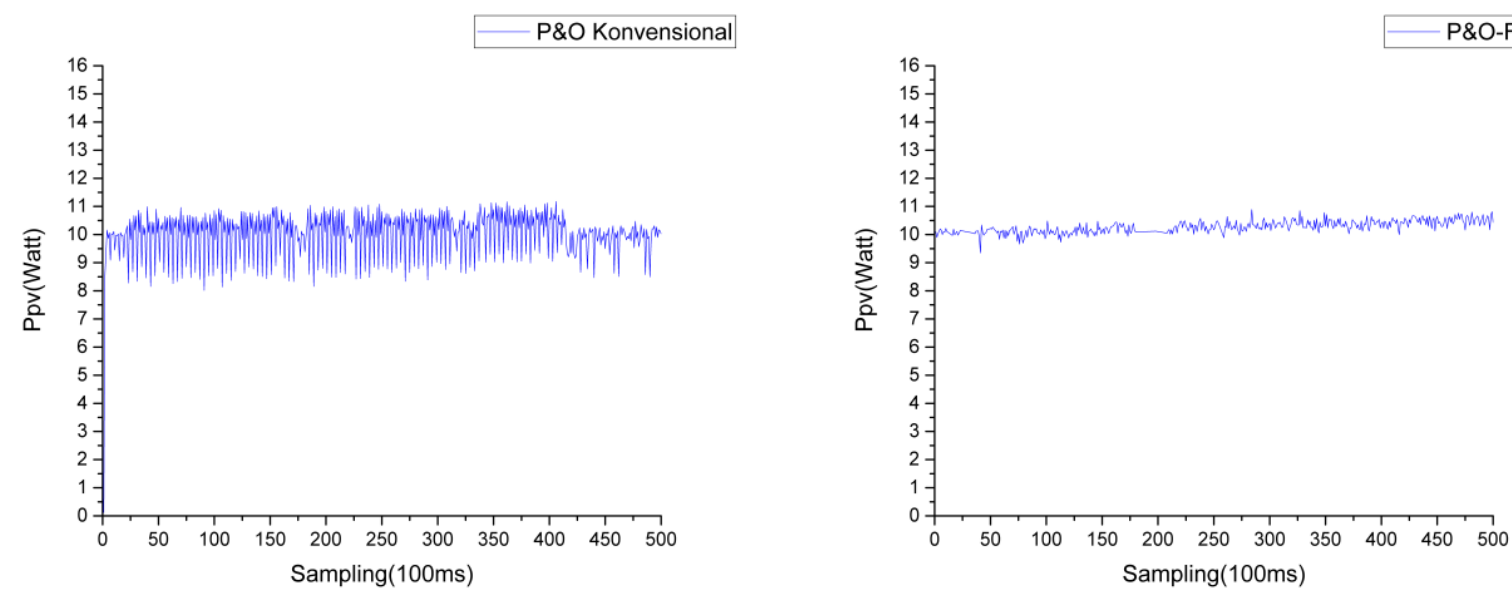

(c) 


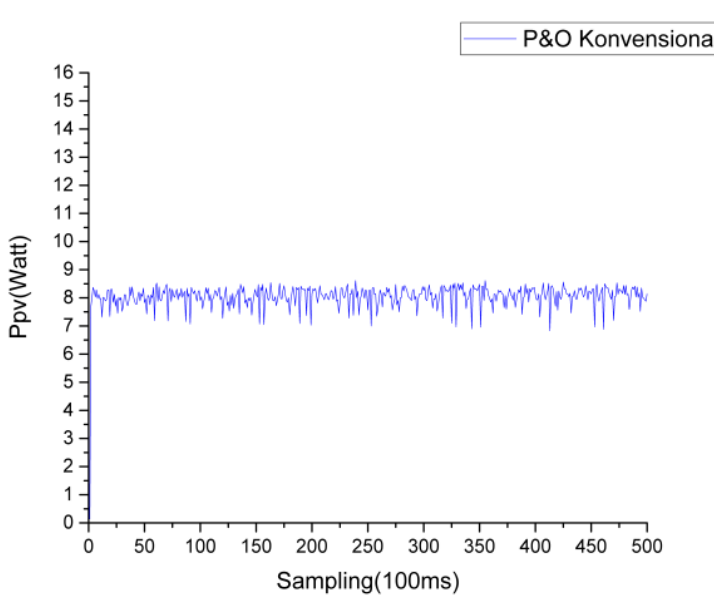

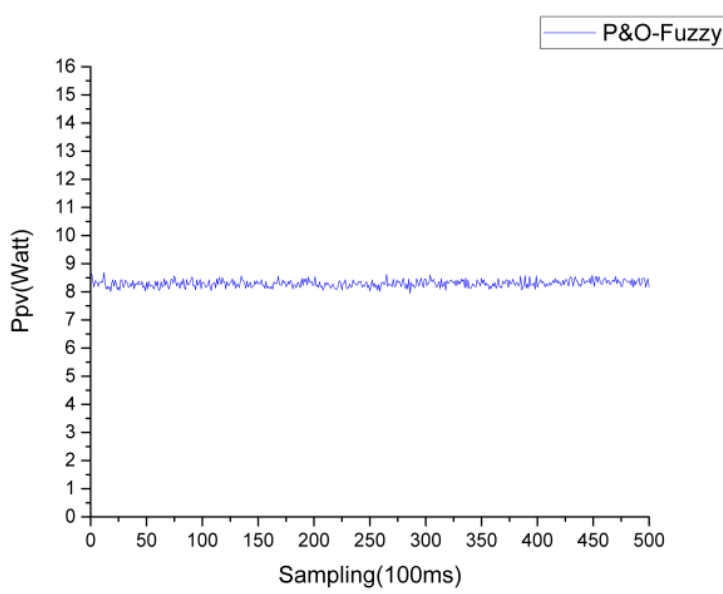

(d)

Gambar 18. Hasil pengujian alat pada (a) Iradiasi $330 \mathrm{~W} / \mathrm{m}^{2}$, (b) Iradiasi $280 \mathrm{~W} / \mathrm{m}^{2}$, (c) Iradiasi $230 \mathrm{~W} / \mathrm{m}^{2}$, (d) Iradiasi $185 \mathrm{~W} / \mathrm{m}^{2}$

\section{PENUTUP}

Implementasi MPPT dengan algoritma Perturb and Observe-Fuzzy (P\&O-Fuzzy) dapat disimulasikan dengan menggunakan software Matlab 2015b atau versi yang lebih baru. Implementasi alat secara nyata menggunakan Arduino Uno sebagai kontrol utama, sensor tegangan dan sensor arus ACS712 sebagai feedback kontrol MPPT. Rata-rata efisiensi alat dengan algoritma P\&O-Fuzzy sebesar $89,67 \%$ sedangkan algoritma Perturb and Observe konvensional sebesar 85,03\%. Saran untuk penelitian selanjutnya adalah penggunaan PV Simulator agar dapat mengatur parameter pengujian dengan mudah dan memvalidasi kesesuaian algoritma.

\section{REFERENSI}

[1] D. Choudhary dan A. R. Saxena, DC-DC Buck-Converter for MPPT of PV System, IJETAE 4(7): 813-821, 2014.

[2] S. C. Hipparagi dan D. K. Prasanna, Maximum Power Point Tracker for PV Solar Panels Using SEPIC Converter, IJSR 4(5): 403-407, 2015.

[3] S.M. Cinar dan E. Akarslan, On the Design an Intelligent Battery Charge Controller for PV Panels, JESTR 5(4): 30-34, .2012.

[4] Z. El Khadmiri, et al, A Novel Solar tracker Bassed on Omnidirectional Computer Vision, Journal of Solar Energy 2015(149852): 1-6, 2015.

[5] M.S. Ait Cheik, C. Larbes, G.F. Tchoketch Kebir, dan A. Zerguerras, Maximum Power Point Tracking using Fuzzy Logic Control Scheme, Revue des Energies Renouvelables 10(3): 387-395, 2007.

[6] D. K. Sharma dan G. Purohit, Advanced Perturbation and Observation (P\&O) based Maximum Power Point Tracking (MPPT) of Solar PhotoVoltaic System, Conference Paper IEEE.1-5, 2012.
[7] T. Esram dan P. L. Chapman, Comparison of Photovoltaic Array Maximum Power Point Tracking Techniques, IEE Transaction on Energy Conversion 22(2): 439-449, 2007.

[8] A.K Abdelsalam, M.M. Ahmed, S. Ahmed, dan N.E.Prasad, HighPerformance Adaptive Perturb and Observe MPPT Technoque for photovoltaic-Based Microgrid, IEEE Transactions on Power Electronics 26(4), 1010-1021, 2011.

[9] B. Bendip, F. Krim, H. Belmili, M. F. Almi, dan S. Boulouma, Advanced Fuzzy MPPT Controller for a stand-alone PV system, International Conference on Technologies and Materias for Renewable Energy, Environment and Sustainability, Energy Procedia 50(2014): 383-392 2014.

[10] R. Arulmurugan dan N. S. Vanitha, Intellegent Fuzzy MPPT Controller using Analysis of DC to DC Novel Buck Converter for Photovoltaic Energy System Applications, Proceedings of the 2013 International Conference on Pattern Recognition, Informatics and Mobile Engineering, IEEE, 21-22, 2013.

[11] S. Selvan, K. J. M. Feros, V. Umayal, dan M. Indumathi, Simulation of Fuzzy Logic Control Based MPPT Technique for Photovoltaic System, International Conference on Inovations in Engineering and Technology, 10-14, 2014.

[12] A. Subiyanto, Mohamed dan M. A. Hannan, Iintelligent photovoltaic Maximum Power Point Tracking Controller for Energy Enhancement in Renewable Energy System, Journal of Renewable Energy 2013(901962): 1-9.

[13] Saidi, Ahmed dan C. Benachaiba, Comparison of IC and P\&O algoritms oin MPPT for Grid Conected PV Module, International Conference on Modeling, Identification and Control (ICMIC), IEEE, 213-218, 2016.

[14] F. L. Tofoli, P. D. D. Castro, dan W. J. D. Paula, Comparative Study of Maximum Power Point Tracking Technique for Photovoltaic System, International Journal of Photoenergy 2015(812582): 1-10, 2015. 